University of Wollongong

Research Online

Faculty of Engineering and Information

Faculty of Engineering and Information

Sciences - Papers: Part A

Sciences

$1-1-2016$

Investigation of hydrogen assisted cracking in acicular ferrite using sitespecific micro-fracture tests

Walter L. Costin
University of Adelaide
Oliver Lavigne
University of Adelaide
Andrei Kotousov
University of Adelaide
Reza Ghomashchi
University of Adelaide
Valerie M. Linton
University of Wollongong, vlinton@uow.edu.au

Follow this and additional works at: https://ro.uow.edu.au/eispapers

Part of the Engineering Commons, and the Science and Technology Studies Commons

Research Online is the open access institutional repository for the University of Wollongong. For further information contact the UOW Library: research-pubs@uow.edu.au 


\title{
Investigation of hydrogen assisted cracking in acicular ferrite using site-specific micro-fracture tests
}

\begin{abstract}
Hydrogen assisted cracking (HAC) is a common type of failure mechanism that can affect a wide range of metals and alloys. Experimental studies of HAC are cumbersome due to various intrinsic and extrinsic parameters and factors (associated with stress, hydrogen and the materials microstructure) contributing to the hydrogen crack kinetics. The microstructure of many materials consists of diverse constituents with characteristic features and mechanical properties which only occur in very small material volumes. The only way to differentiate the effect of these individual constituents on the hydrogen crack kinetics is to miniaturise the testing procedures. In this paper we present a new experimental approach to investigate hydrogen assisted crack growth in a microstructural constituent, i.e. acicular ferrite. For this purpose, sharply notched micro-cantilevers were fabricated with a Focus Ion Beam within this selected microscopic region. Acicular ferrite can be found in many ferrous alloys including ferritic weld metal and has specific features that control its intrinsic susceptibility to HAC. These features were characterised via Electron Backscatter Diffraction and the specimens were subsequently loaded under uncharged and hydrogen charged conditions with a nano-indenter. The outcomes of the testing, demonstrated that the threshold stress intensity factor, Kth, to initiate crack propagation in acicular ferrite ranges between 1.56 $\mathrm{MPa} \mathrm{m} 1 / 2$ and $4.36 \mathrm{MPa} \mathrm{m} 1 / 2$. This range is significantly below the values of Kth reported for various ferrous alloys in standard macro-tests. This finding indicates that the mechanisms and resistance to HAC at micro-scale could be very different than at the macro-scale as not all fracture toughening mechanisms may be activated at this scale level.

\section{Disciplines}

Engineering | Science and Technology Studies

\section{Publication Details}

Costin, W. L., Lavigne, O., Kotousov, A., Ghomashchi, R. \& Linton, V. (2016). Investigation of hydrogen assisted cracking in acicular ferrite using site-specific micro-fracture tests. Journal of Materials Science and Engineering A, 651 859-868.
\end{abstract}




\title{
Investigation of hydrogen assisted cracking in acicular ferrite using site-specific micro-fracture tests
}

\author{
Walter L. Costin ${ }^{\mathrm{a}}$, Olivier Lavigne ${ }^{\mathrm{a}, *}$, Andrei Kotousov ${ }^{\mathrm{a}}$, Reza Ghomashchi ${ }^{\mathrm{a}}$, Valerie Linton ${ }^{\mathrm{b}}$ \\ a School of Mechanical Engineering, The University of Adelaide, SA 5005, Australia \\ ${ }^{\mathrm{b}}$ Energy Pipelines Cooperative Research Centre, Faculty of Engineering, University of Wollongong, NSW 2522, Australia
}

\section{A R T I C L E I N F O}

\section{Article history:}

Received 21 September 2015

Received in revised form

13 November 2015

Accepted 14 November 2015

Available online 1 December 2015

Keywords:

EBSD

Micromechanics

Steel

Welding

Hydrogen embrittlement

Stress intensity factor threshold

\begin{abstract}
A B S T R A C T
Hydrogen assisted cracking (HAC) is a common type of failure mechanism that can affect a wide range of metals and alloys. Experimental studies of HAC are cumbersome due to various intrinsic and extrinsic parameters and factors (associated with stress, hydrogen and the materials microstructure) contributing to the hydrogen crack kinetics. The microstructure of many materials consists of diverse constituents with characteristic features and mechanical properties which only occur in very small material volumes. The only way to differentiate the effect of these individual constituents on the hydrogen crack kinetics is to miniaturise the testing procedures. In this paper we present a new experimental approach to investigate hydrogen assisted crack growth in a microstructural constituent, i.e. acicular ferrite. For this purpose, sharply notched micro-cantilevers were fabricated with a Focus Ion Beam within this selected microscopic region. Acicular ferrite can be found in many ferrous alloys including ferritic weld metal and has specific features that control its intrinsic susceptibility to HAC. These features were characterised via Electron Backscatter Diffraction and the specimens were subsequently loaded under uncharged and hydrogen charged conditions with a nano-indenter. The outcomes of the testing, demonstrated that the threshold stress intensity factor, $K_{\text {th }}$, to initiate crack propagation in acicular ferrite ranges between $1.56 \mathrm{MPa} \mathrm{m}^{1 / 2}$ and $4.36 \mathrm{MPa} \mathrm{m}^{1 / 2}$. This range is significantly below the values of $K_{\mathrm{th}}$ reported for various ferrous alloys in standard macro-tests. This finding indicates that the mechanisms and resistance to HAC at micro-scale could be very different than at the macro-scale as not all fracture toughening mechanisms may be activated at this scale level.
\end{abstract}

(c) 2015 Elsevier B.V. All rights reserved.

\section{Introduction}

Hydrogen assisted cracking (HAC) is a prevalent failure mechanism that affects most metals and alloys. Johnson in 1875 was the first to report about the deleterious effects of hydrogen on the mechanical properties of iron and steels [1]. This phenomenon is historically referred to as Hydrogen Embrittlement (HE) because macroscopically the presence of hydrogen in metals generally leads to reduction in fracture energy and ductility promoting brittle failure. The term HAC was later suggested by Beachem who argued that hydrogen assisted crack propagation may imply microscopic deformation processes that are not necessarily the result of the cessation, restriction, or exhaustion of ductility [2], however, from a mechanistic point of view both designations refer to the same phenomenon.

\footnotetext{
* Corresponding author.

E-mail addresses: Olivier.lavigne@adelaide.edu.au, lavigneolivier@hotmail.com (O. Lavigne).
}

HAC can be classified as either Internal Hydrogen Assisted Cracking (IHAC), which is the main focus of the current paper, or Hydrogen Environment Assisted Cracking (HEAC). In IHAC, atomic hydrogen can be introduced throughout the microstructure by manufacturing operations (casting, welding, surface-chemical cleaning, electrochemical machining, electroplating, and heat treatment) as well as due to environmental exposure (cathodic electrochemical reactions or gaseous hydrogen exposure). Subcritical crack growth can occur if a hydrogen charged material with a susceptible microstructure is subjected to a sufficient stress level. Meanwhile, HEAC involves the conjoint action of mechanical loading and chemical reaction, i.e. the stress is necessary during the hydrogen uptake to facilitate cracking. Therefore, IHAC and HEAC are distinguished by the source of the supplied hydrogen but share common aspects, i.e. cracking occur in both cases when the three causal conditions are simultaneously present: (1) susceptible microstructure, (2) sufficiently high levels of hydrogen and (3) stress [3].

Hydrogen is widely considered as one of the future sources of 
clean energy [4]. A large scale of production, storage and transportation of hydrogen is likely to be escaladed in the next few decades. Because of the technological importance of HAC for the past, present and future applications, greater amount of efforts have been directed to the development of experimental and theoretical approaches to predict and evaluate the effect of hydrogen on the life expectancy and integrity of structural components [2,3,5-9]. However, HAC continues to plague applications of, specifically, high strength metals and alloys [3]. Various, often controversial views $[7,10-14]$ have been proposed to describe the physical mechanisms by which hydrogen actually affects plasticity and fracture resistance in metals. Detailed reviews of these approaches can be found in $[3,15]$. However, it is the Linear Elastic Fracture Mechanics that provides a basis allowing the incorporation of hydrogen cracking failure mechanism into structural integrity management [16]. In accordance with this fracture theory pioneered by Naval Research Laboratory in 1965 [17] a single stress related parameter, the stress intensity factor, $K$, governs the crack initiation and crack growth rates. This concept was confirmed by many other studies over the past 60 years $[3,18-22]$. From the structural integrity point of view three characteristics of the fracture behaviour have to be identified experimentally: (a) a threshold stress intensity factor, $K_{\text {th }}$ (or other terminology), below which crack does not propagate, (b) crack growth rates $(\mathrm{d} a / \mathrm{d} t)$ at $K>K_{\text {th }}$ and (c) fracture toughness $K_{\mathrm{C}}$. Effective laboratory methods have been developed and standardised [23] to determine the threshold and kinetics for hydrogen assisted cracking, which are necessary for the safe design of structures subjected to the risk of HAC. IHAC testing procedures may involve several stages: a fracture mechanics specimen, typically fatigue pre-cracked, which can be stressed under either constant or rising load, crack mouth opening displacement or constant $K$. These procedures are substantially more complex and time consuming in comparison with the standard fracture testing. For example, the identification of the threshold stress intensity factor, $K_{\mathrm{th}}$, requires several thousand hours of testing time [23].

Due to a wide range of parameters affecting the HAC phenomenon (such as the rate and mode of loading, constraint conditions, hydrogen charging method, temperature, specimen size, diverse microstructural factors, etc.) the outcomes of conventional HAC tests demonstrate a large scatter [5]. In the development of experimental methods to characterise HAC over the past 50 years, a great effort has been directed to eliminate these diverse parameters influencing the reproducibility of the test results. In addition, the utilisation of the stress intensity factor and plane strain conditions as well as controlled hydrogen charging allowed an accurate measure of the mechanical stress and environmental conditions, two main factors affecting HAC. However, the microstructure of metal and alloys (which is the third main factor affecting HAC) typically consists of diverse constituents with specific features and mechanical properties that only occur in microscopic volumes. To investigate the HAC susceptibility of such small volumes it is therefore necessary to significantly reduce the size of the specimens down to the characteristic size of the individual microstructural constituent.

Katz et al. [24] were the first who proposed the application of nano-indentation to examine the micro-mechanisms of hydrogen related failures. This idea was extended by Barnoush and Vehoff [5] who presented a method for determining the onset of plasticity in very small volumes (perfect crystals) subjected to hydrogen charging. Several different materials were tested with this method. For example, it was found that hydrogen reduces the critical stress required for the onset of plasticity. However, this method is not capable of providing a quantitative evaluation of fracture properties similar to conventional fracture tests, such as stress intensity factor threshold or crack growth rates. It seems that the only viable approach for a direct quantitative evaluation of the fracture properties of very small material volumes is the miniaturisation of fracture specimens and testing down to micro-scale [25].

The miniaturisation of fracture tests became possible over the past decade with an increasing efficiency and accuracy of Focused Ion Beam (FIB) workstations, which has resulted in a reproducible fabrication of micro-scaled specimens. Several researchers have already employed FIB micromachining to fabricate micro-pillars for performing compression tests on uncharged and hydrogen charged specimens [26,27]. These experiments demonstrated the hydrogen-deformation interrelationships at microscopic scales. However, FIB micro-machining also allows fabricating standard fracture specimens with microscopic dimensions $[28,29]$. This idea has been realised in the current work to investigate the effects of hydrogen on the crack kinetics in a selected microstructural constituent with particular features. Sharply notched micro-cantilevers were fabricated with a FIB into a localised region fully consisting of acicular ferrite which is a common microstructural constituent of ferritic weld metal and alloys. This microstructural region has characteristic features that largely determine its mechanical properties as well as its susceptibility to HAC. The microcantilevers were characterised via Electron Backscatter Diffraction (EBSD) and subsequently tested under uncharged and hydrogen charged conditions with a nano-indenter. However, HAC fracture testing standards, developed for macro-examinations, could not be followed precisely in our experimental campaign, specifically in terms of the test duration to identify the onset of hydrogen cracking or $K_{\mathrm{th}}$, fatigue pre-cracking and realisation of plane strain conditions. Constant loading was applied for twelve hours to simulate the time delayed nature of the IHAC in a micro-scale specimen. Unexpectedly, the fracture mechanics characteristics derived from the present tests were found to be very different to the corresponding values reported for conventional sized fracture specimens.

\section{Material and methods}

Weld metal is an example of a material that typically consists of diverse microstructural constituents with distinctive features and mechanical properties. The properties of individual constituents can only be revealed when testing small material volumes, and are therefore not directly assessable with conventional methods of mechanical testing $[5,30]$. It is well-known that the presence of hydrogen can significantly compromise the structural integrity of the weld metal (as well as of the heat affected zone). Hydrogen Assisted Cold Cracking (HACC), which is a particular manifestation of IHAC, is a well-known weld failure mechanism that may occur after the deposited weld has cooled down to temperatures below $200{ }^{\circ} \mathrm{C}$. A critical structural defect can be developed within minutes to even days after welding [31]. Due to its time delayed nature the onset of Weld Metal Hydrogen Assisted Cold Cracking (WM HACC) may be undetected and, eventually, result in catastrophic failure.

\subsection{Material-microstructural constituent}

A weld metal specimen was sourced from API $5 \mathrm{~L}$ grade $\mathrm{X} 70$ samples welded with $4 \mathrm{~mm}$ diameter E6010 cellulosic electrodes. The welding procedure is presented in details in [32]. Under these welding conditions, the yield strength of the weld metal is expected to range between the yield strengths of the E6010 electrode (420 MPa) and the X70 parent metal (480 MPa).

A localised region of the weld metal specimen consisting of acicular ferrite was identified for further micro-fracture tests (Fig. 1a and b). This microstructural constituent represents a 

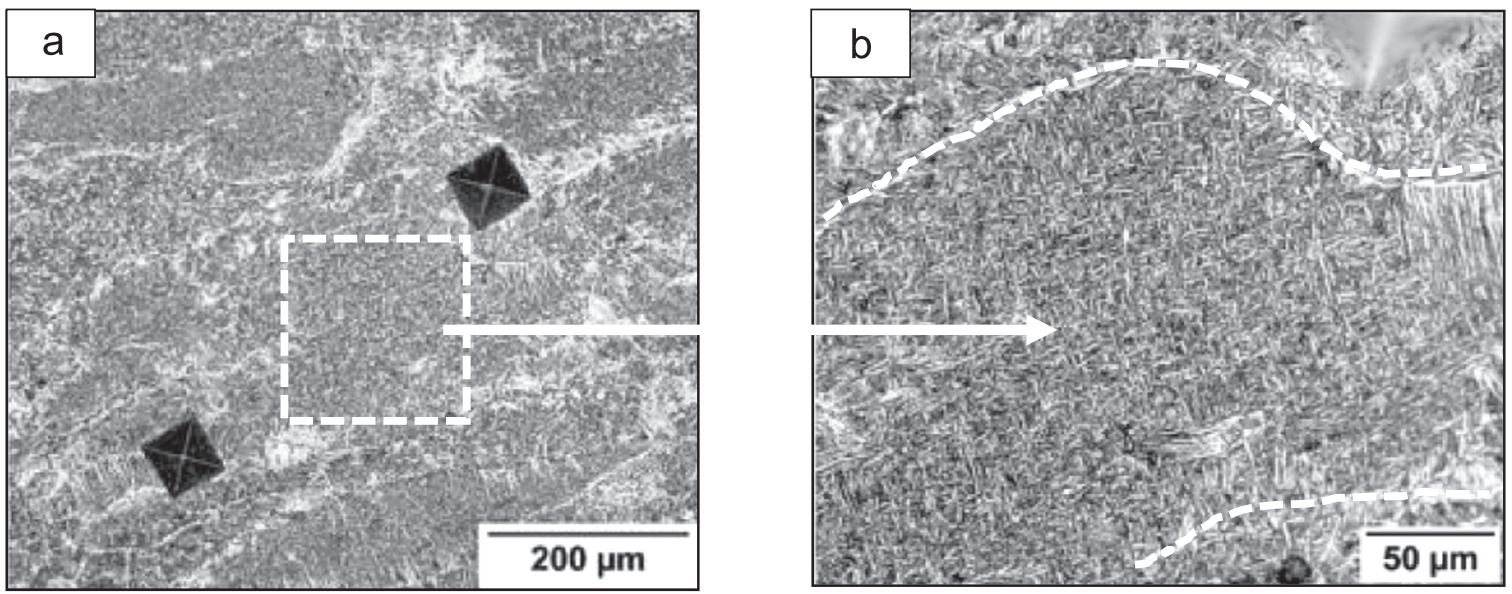

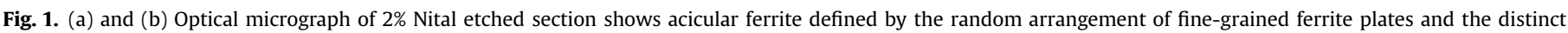
interlocking morphology.

particular interest for the weld metal integrity. Previous investigations reported that of all typical ferritic weld metal microstructures, acicular ferrite seems to have the most beneficial impact on the strength, toughness as well as the HACC resistance of welded joints $[33,34]$. This was mainly related to a small grain size and high density of high angle grain boundaries, which apparently increase the resistance to cleavage like fracture and simultaneously acts as a hydrogen trap, thereby preventing the hydrogen to diffuse to more HACC susceptible regions [34].

\subsection{FIB fabrication of the micro-cantilevers}

The fabrication of the micro-cantilevers within the selected region was accomplished with a FEI Helios Nanolab 600 Dual Beam $^{\mathrm{TM}}$ FIB. The first step of the process was to mill three trenches with a stair step pattern mode for each micro-cantilever using an intense ion beam current density $(21 \mathrm{nA} / 30 \mathrm{kV})$. The sample was tilted $90^{\circ}$ with respect to the incident ion beam. The ratio between the final specimen length and trench depth had to be selected appropriately to ensure that the deflected cantilever do not touch the bottom of the trench during loading. In this case the trench depth was $50 \mu \mathrm{m}$ and the final cantilever length was $75 \mu \mathrm{m}$. For the second step of the fabrication process an ion beam with a less intense current density $(2.8 \mathrm{nA} / 30 \mathrm{kV})$ was used to mill (polish) the sidewalls. The sample was then tilted $45^{\circ}$ to the incident ion beam to cut the bottom of the micro-beam. The operation was then repeated on the other side to create a symmetric pentagonal profile. Finally, a stair step pattern and an ion beam with a very low intensity $(0.46 \mathrm{nA} / 30 \mathrm{kV})$ were utilised to mill a sharp notch of $8 \mu \mathrm{m}$ depth, $16 \mu \mathrm{m}$ away from the beam support. Fig. 2 shows the final geometry of a typical notched micro-cantilever fabricated out of the selected microstructure. The ion-induced secondary electron image reveals that the entire volume of the fabricated microcantilever consists predominantly of acicular ferrite (Fig. 2a). Fig. $2 \mathrm{~b}$ shows the detailed dimensions of the sample. Preliminary micro-fracture tests of three cantilevers with slightly different dimensions fabricated within acicular ferrite [35] had demonstrated a reproducible behaviour. On this basis, two cantilevers were manufactured for the purpose of the current study. One cantilever was charged with hydrogen and then mechanically loaded; the other specimen was tested under as-fabricated (uncharged) conditions and was utilised as a reference. The deviations of the dimensions between the individual micro-cantilevers were within $\pm 100 \mathrm{~nm}$ range.

The lattice damage caused by FIB milling and imaging was evaluated using the program TRIM 2013 [36]. Simulations were generated for $30 \mathrm{kV} \mathrm{Ga}^{+}$ions impinging at an incidence angle of $0^{\circ}$ (imaging) and at a glancing angle of $89^{\circ}$ (milling of the sidewalls) onto the surface of an iron target. The distributions were calculated for 1000 ions for each of the incidence angles. The
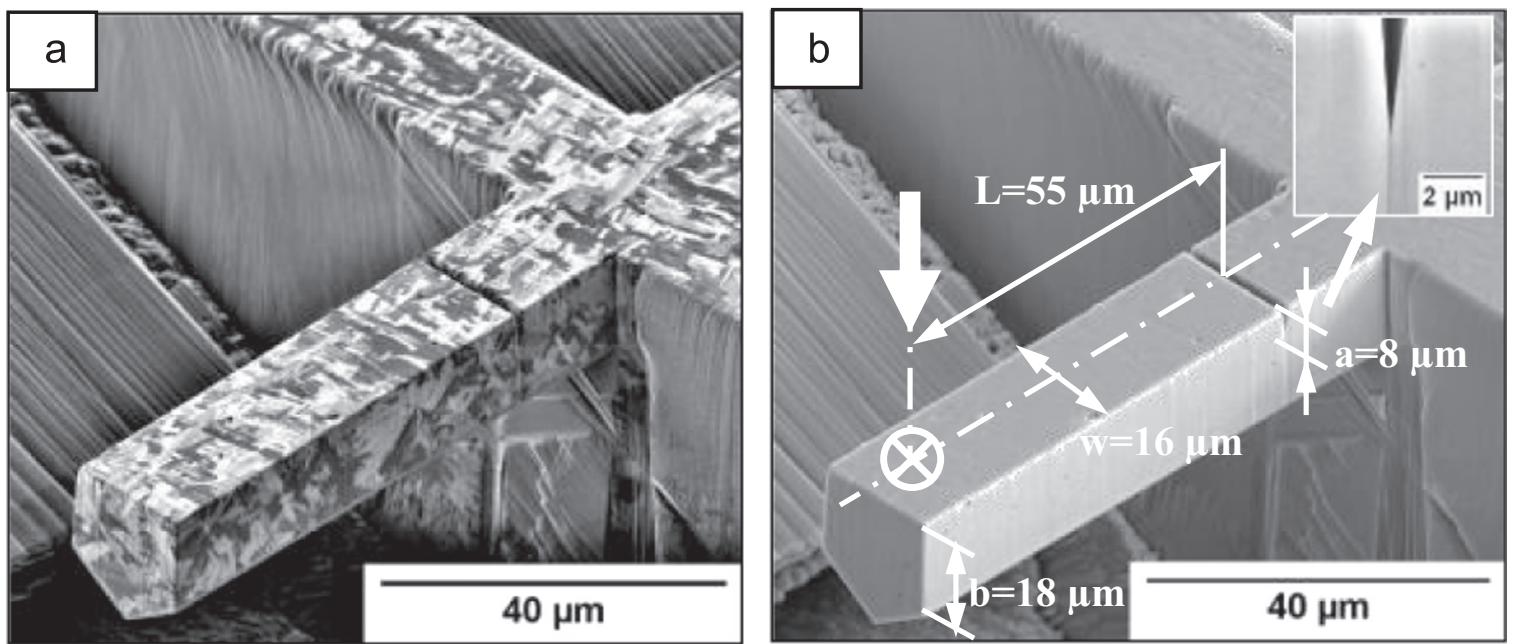

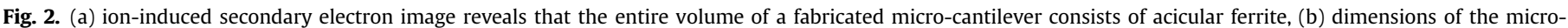
cantilever. 
lattice damage caused by FIB milling and imaging was respectively evaluated to approximately $20 \mathrm{~nm}$ and $30 \mathrm{~nm}$ in material's depth. These simulations were consistent with the maximum damaged layer measured by TEM and Auger electron spectroscopy on copper under perpendicular ion impact at $30 \mathrm{kV}$ (approximately $50 \mathrm{~nm}$ ) [37]. The size of the damaged layer was negligible with respect to the dimensions of the micro-cantilevers and was, therefore, expected have no significant effect on the mechanical properties of the fabricated specimens $[37,38]$.

\subsection{EBSD data collection and processing}

EBSD was applied to obtain a detailed quantitative characterisation of grain size, grain boundary misorientation, texture, and phase identity within the selected region. EBSD data was directly collected from the plane on top of the micro-cantilevers using the FEI Helios Nanolab 600 equipped with an EBSD detector (EDAX Hikari $^{\mathrm{TM}}$ ) and the EDAX OIM ${ }^{\mathrm{TM}}$ Data Collection and Analysis 5.2 software (TSL Co., Ltd.). Acceleration voltage of SEM beam for the EBSD measurement was $20 \mathrm{kV}$ and the beam current was $2.1 \mathrm{nA}$. The step size was $20 \mathrm{~nm}$ with a hexagonal scan grid. The sample surfaces were polished using a semi-automatic LaboForce polishing machine (Struers). The final polishing was achieved using a porous neoprene disc with a colloidal silica suspension $(0.04 \mu \mathrm{m})$ prior to the micro-beam fabrication step.

\subsection{Hydrogen charging}

For the pre-charged sample, the as-fabricated micro-cantilever was electrochemically charged with hydrogen for 90 min by applying a cathodic current density of $-20 \mathrm{~mA} \mathrm{~cm}^{-2}$ in a $0.05 \mathrm{M}$ $\mathrm{H}_{2} \mathrm{SO}_{4}$ solution. By using these parameters it was possible to maintain the surface integrity of the specimen (Fig. 3).

The hydrogen electrochemical oxidation method was applied to estimate the total amount of hydrogen absorbed during the charging procedure [39-41]. The oxidation currents were obtained by keeping the specimens at a potential of $+168 \mathrm{mV}_{\mathrm{Ag} / \mathrm{AgCl}}$ in a deaerated $0.2 \mathrm{M} \mathrm{NaOH}$ solution for $2 \mathrm{~h}$. This potential, which is higher than the hydrogen equilibrium potentials and lower than the passive film breakdown potential of the metal, allowed the oxidation reaction of the metal to be limited in this solution (see the uncharged reference curve, Fig. 4), and the oxidation reaction of hydrogen to be induced simultaneously. The total quantity of the hydrogen absorbed $\left(Q_{H}^{a b s}\right)$ by the weld metal can be thus expressed as:

$Q_{H}^{a b s}=\int_{0}^{\mathrm{t}}\left[I_{H}(\mathrm{t})-I_{\text {ref }}(\mathrm{t})\right] \mathrm{dt}, \quad$ at $E_{\text {anodic }}=$ const.

where $I_{H}(t)$ is the oxidation current for the hydrogen charged specimen and $I_{r e f}(t)$ is the oxidation current for the specimen

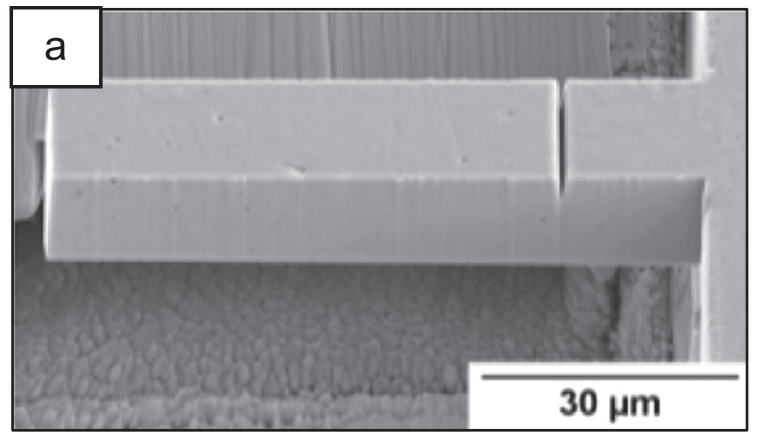

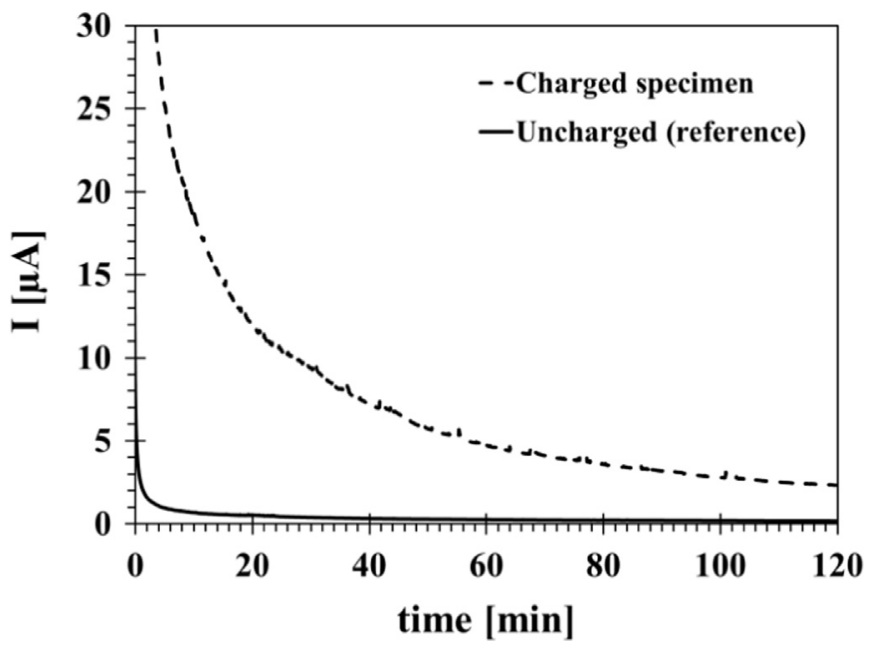

Fig. 4. Hydrogen discharging process under anodic polarisation $\left(+168 \mathrm{mV}_{\mathrm{Ag} / \mathrm{AgCl}}\right)$ in $0.2 \mathrm{M} \mathrm{NaOH}$ for the electrochemically charged specimen (at $20 \mathrm{~mA} \mathrm{~cm}^{-2}$ for $90 \mathrm{~min}$ in $0.05 \mathrm{M} \mathrm{H}_{2} \mathrm{SO}_{4}$ solution) and the reference specimen (uncharged).

without hydrogen (Fig. 4). According to Faraday's law, hydrogen concentration, $C_{H}$, is related to $Q_{H}^{a b s}$ by the relation:

$C_{H}=\frac{Q_{H}^{a b s}}{z F v}$

where $F$ is the Faraday constant $\left(96487 \mathrm{C} \mathrm{mol}^{-1}\right), \mathrm{v}$ is the effective volume of the specimen (in this case $0.5754 \mathrm{~cm}^{3}$ ) and $z$ is the number of electrons $(z=1)$. With the selected charging parameters, the hydrogen concentration in the specimen was thus measured as $1.038 \times 10^{-6} \mathrm{~mol} \mathrm{~cm}^{-3}$, which corresponds to $0.132 \mathrm{ppm}$.

All electrochemical tests were conducted with a Gamry interface $1000^{\mathrm{TM}}$, using the specimens as the working electrode, a platinum mesh as the counter electrode and a silver/silver chloride electrode as the reference. All electrolytes used were prepared with analytical grade reagents and distilled water. The experiments were all performed at room temperature.

\subsection{Stress intensity factor evaluation}

An IBIS software controlled nanoindentation system (FischerCripps Laboratories Pty Ltd.) was used as a load cell to apply a bending force near the free end of the notched micro-cantilevers, while recording the load-deflection curves. The loading type was displacement-controlled with a loading displacement rate of $0.02 \mu \mathrm{m} \mathrm{s}^{-1}$ and a maximum displacement (beam deflection) for uncharged specimen of $18.5 \mu \mathrm{m}$ because of the limitations of the instrument (nano-indenter). The selected indenter tip was spherical with a relatively large diameter of $40 \mu \mathrm{m}$ to avoid penetration

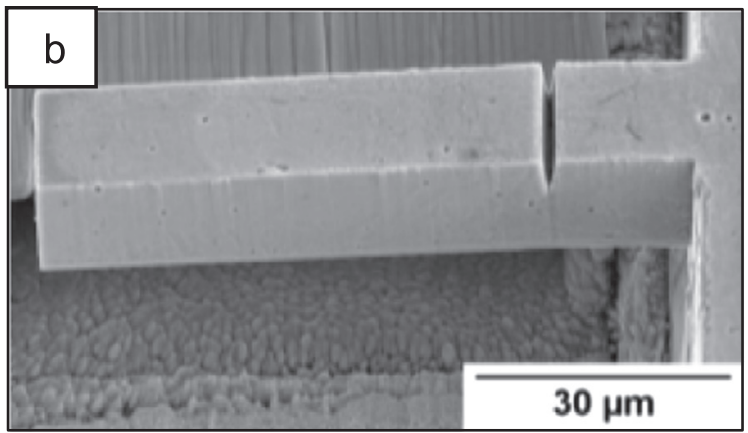

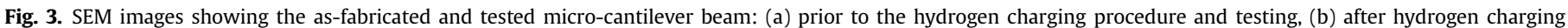
procedure and testing (at the constant load of $14 \mathrm{mN}$ ) showing the conservation of the surface integrity despite the hydrogen charging procedure. 

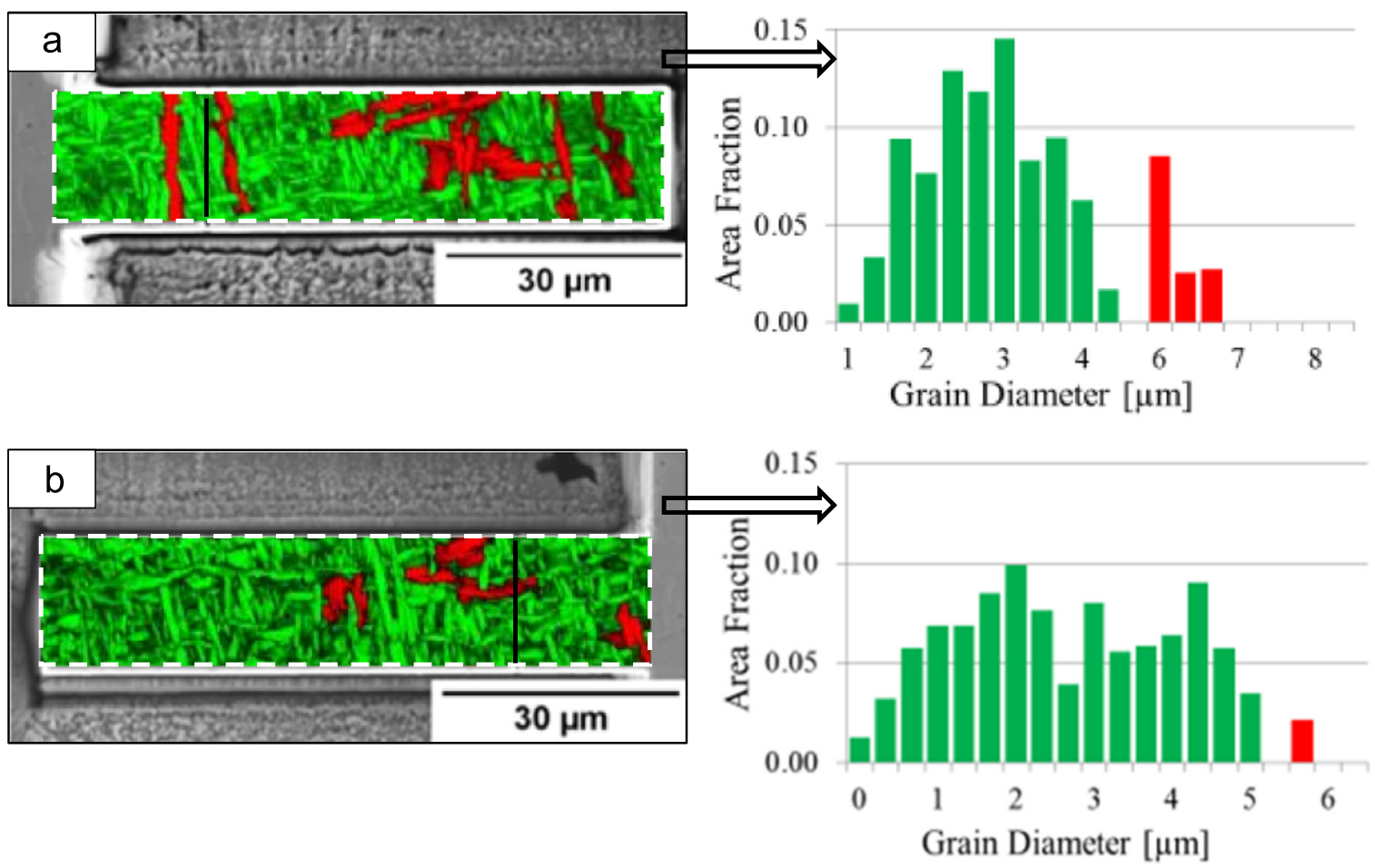

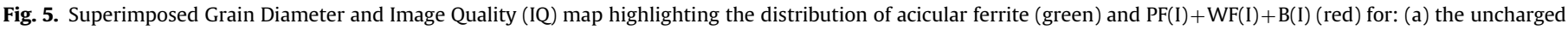

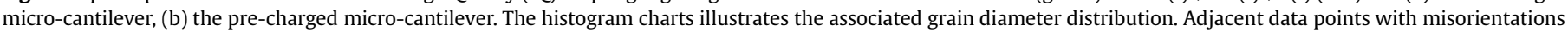

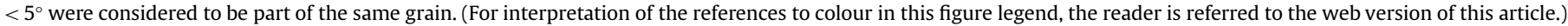

and to minimise the local deformation in the contact area. The measured displacements, therefore, were dominated by the beam deflection rather than the deformation in the area of contact.

In order to simulate the time delayed nature of HACC, constant loads ( $5 \mathrm{mN}$ and $14 \mathrm{mN}$ ) were applied for $12 \mathrm{~h}$ to the hydrogen pre-charged micro-cantilever.

The stress intensity factors $K_{I}$ corresponding to the pentagonal cross-section of the micro-cantilevers were calculated from the following equation [25]:

$K_{I}=\sigma \sqrt{\pi a} F\left(\frac{a}{b}\right)$

where $\sigma$ is the nominal stress, $a$ is the notch depth $(8 \mu \mathrm{m})$ and $F(a / b)$ is a dimensionless shape factor, which is related to the specimen geometry. For a cantilever subjected to a bending force, $P, \sigma$ can be calculated as:

$\sigma=\frac{P L y}{I}$,

where $P$ is the applied load, $L$ is the distance between the notch and the point of loading on the cantilever (Fig. 2b), I is the moment of inertia of the beam cross section, and $y$ is the vertical distance between the upper surface and the neutral plane. I and $y$ were calculated using the following equations [25]:

$I=\frac{w b^{3}}{12}+\left(y-\frac{b}{2}\right)^{2} b w+\frac{w^{4}}{288}+\left[\frac{b}{6}+(b-y)\right]^{2} \frac{w^{2}}{4}$,

$y=\frac{\frac{b^{2} w}{2}+\frac{w^{2}}{4}\left(b+\frac{w}{6}\right)}{b w+\frac{w^{2}}{4}}$,

where $b$ is the height of the parallel vertical face $(18 \mu \mathrm{m})$ and $\mathrm{w}$ is the width of the micro-beam $(16 \mu \mathrm{m})$, (see Fig. $2 \mathrm{~b})$. The equation for the dimensionless shape factor, $F$, was provided by Di Maio and Roberts [25] who conducted extensive finite element simulations for a wide range of specimen geometries and provided the following equation for $0.3 \leq\left(\frac{a}{b}\right) \leq 0$. 5 :

$$
\begin{aligned}
F\left(\frac{a}{b}\right)= & 1.85-3.38\left(\frac{a}{b}\right)+13.24\left(\frac{a}{b}\right)^{2}-23.26\left(\frac{a}{b}\right)^{3} \\
& +16.8\left(\frac{a}{b}\right)^{4},
\end{aligned}
$$

For the fabricated specimens (Fig. 2b), we have: $I=1.5545 \times 10^{-8} \mathrm{~mm}^{4}, y=0.01112 \mathrm{~mm}$, and $F(a / b)=1.58$ at $a /$ $b=0.44$.

The applicability of Eqs. (3)-(7) to the current specimen geometry was also verified with 3D linear-elastic finite element calculations. These calculations demonstrated that the difference between the numerical results and the analytical predictions is less than $20 \%$. For simplicity reasons the analytical approach was selected for the quantitative analysis of the micro-scale testing results. These results are presented in Section 4.

\section{Results}

\subsection{EBSD characterisations}

The microstructural features for the fabricated micro-cantilevers were characterised via EBSD before hydrogen charging and mechanical loading as presented below.

\subsubsection{Comparison of the microstructural architecture}

The Grain Diameter map in Fig. 5a and b highlights the morphology and size distribution of individual grains according to their Equivalent Circular Area Diameter (green $<5 \mu \mathrm{m}$ or red $\geq 5 \mu \mathrm{m}$ ) for the uncharged and pre-charged micro-cantilevers respectively. The histogram charts illustrate the distribution of the 
Table 1

Ratio between the phase transformation products and average grain diameter for both uncharged and pre-charged micro-cantilevers.

\begin{tabular}{llll}
\hline & $\mathrm{AF}(\%)$ & $\begin{array}{l}\mathrm{PF}(\mathrm{I})+\mathrm{WF}(\mathrm{I})+\mathrm{B} \\
(\mathrm{I})(\%)\end{array}$ & $\begin{array}{l}\text { Average grain diameter } \\
(\mu \mathrm{m})\end{array}$ \\
\hline Uncharged specimen & 86 & 14 & $3.25 \pm 1.17$ \\
Pre-charged specimen & 94 & 6 & $2.97 \pm 1.05$ \\
\hline
\end{tabular}

different grain diameters within the aggregate. The data was used to determine the ratio between the percentage of acicular ferrite (AF) and other ferritic phases of primary ferrite $\mathrm{PF}(\mathrm{I})$, Widmanstätten ferrite $\mathrm{WF}(\mathrm{I})$ and bainite $\mathrm{B}(\mathrm{I})$ as well as the average grain diameter of the micro-cantilevers, i.e. $A F+P F(I)+W F(I)+B$ (I) aggregate, (Table 1). The identification of the different phases was based on the size and shape of the individual grains according to the classification scheme for microstructures in steel welds proposed by Thewlis [42]. The results show that for the precharged micro-cantilever the proportion of acicular ferrite was slightly higher and the average grain diameter consequently lower than that for the uncharged micro-cantilever.

\subsubsection{Comparison of grain boundary characteristics}

The map in Fig. 6a and b highlights the grain boundary distribution of acicular ferrite in the uncharged and pre-charged micro-cantilevers respectively. The main proportion of boundaries were high angle boundaries (misorientation $>15^{\circ}$ ). The complete absence of grains with misorientation differences in the approximate range of $20-47^{\circ}$ indicates that all the ferrite plates were formed within the same prior austenite grain $[43,44]$. The comparison of the grain boundary misorientation distributions between the uncharged and the pre-charged micro-cantilever shows no significant variations (Table 2 ).

The EBSD characterisations confirmed that the microstructure
Table 2

Grain boundary length distribution (in $\mu \mathrm{m}$ ).

\begin{tabular}{llll}
\hline & $0.5-15^{\circ}$ & Coincident site lattice $\Sigma 3$ & $15-180^{\circ}$ \\
\hline Uncharged specimen & 1120 & 216 & 1284 \\
Pre-charged specimen & 1191 & 331 & 1378 \\
\hline
\end{tabular}

was largely uniform across the specimens and the variations of the microstructural features between the fabricated micro-cantilevers were almost negligible.

\subsection{Estimation of the acicular ferrite yield strength}

The nano-indenter equipped with a Berkovich diamond tip was used to measure the hardness and Young's modulus of the considered acicular ferrite region. Three indentation tests at a maximum load of $50 \mathrm{mN}$ were conducted and the results were averaged as follows. The Young's modulus, universal hardness and Vickers hardness were measured as respectively: $195 \pm 13 \mathrm{GPa}$, $3.36 \pm 0.12 \mathrm{GPa}$ and $317 \pm 11 \mathrm{HV}$. An estimation of the yield strength of the acicular ferrite can be made using the empirical relationship between strength and hardness for X65 as derived in [45]:

$\sigma_{Y}=2 \mathrm{HV}+105$

which results in a yield strength of $740 \mathrm{MPa}$. The yield strength of the acicular ferrite has been reported to be in the range of 480$750 \mathrm{MPa}$ [46-49]. The differences can be attributed to the steel composition as well as the testing procedures.

\subsection{Mechanical loading}

Fig. 7 shows the load-deflection curves for the uncharged and
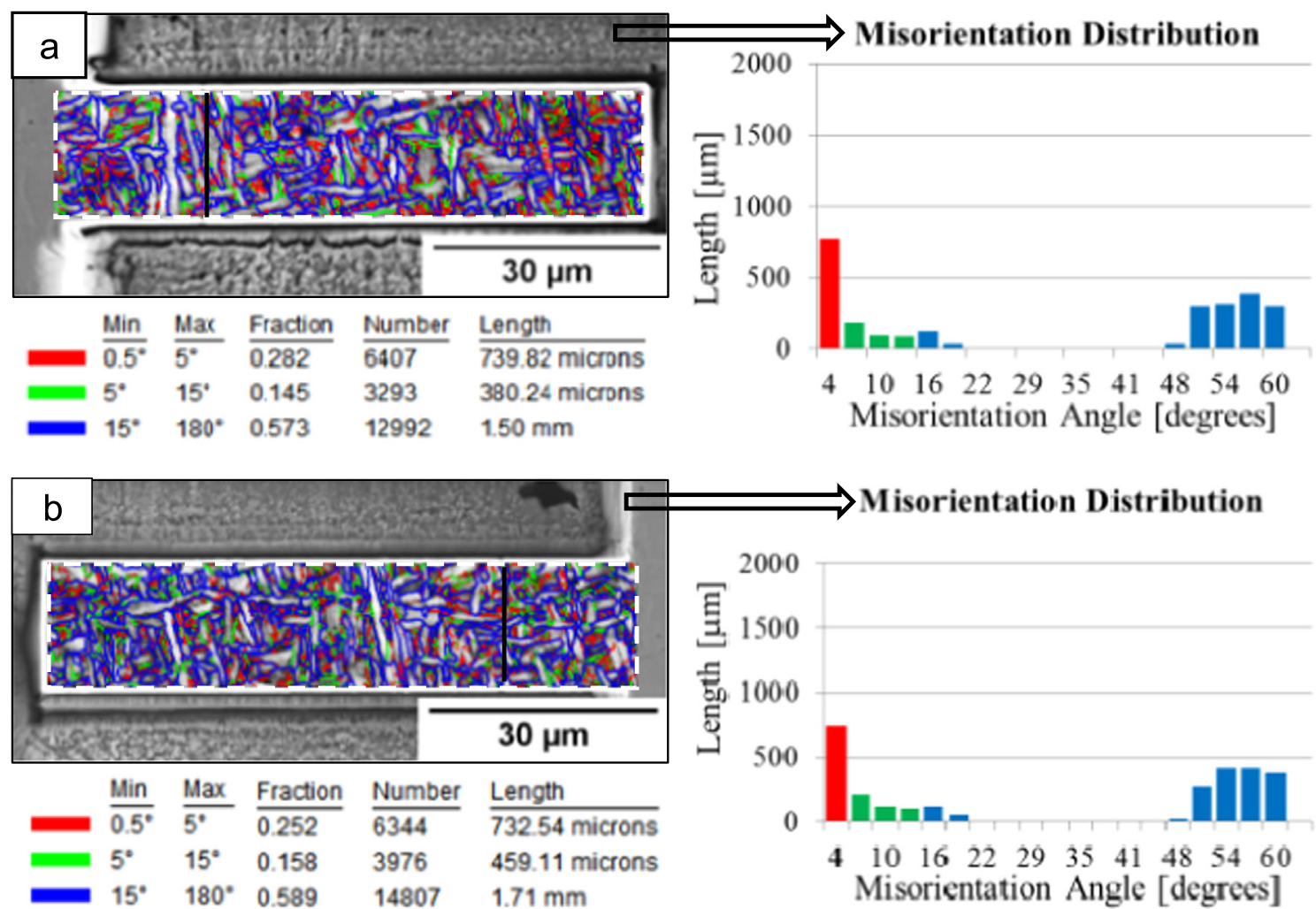

Misorientation Distribution

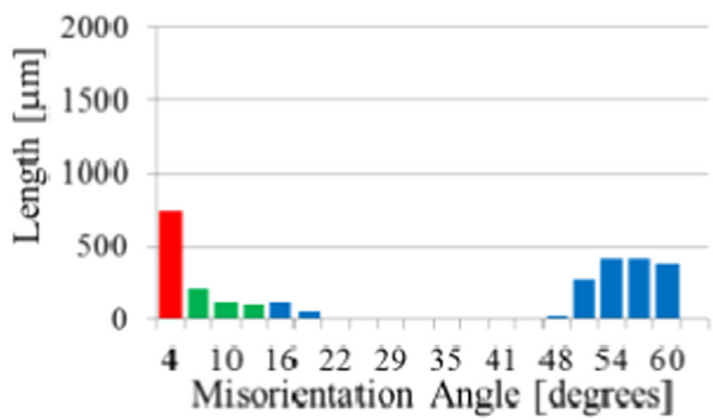

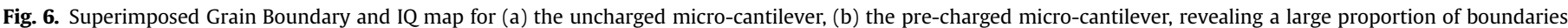
with misorientation $>15^{\circ}$. 


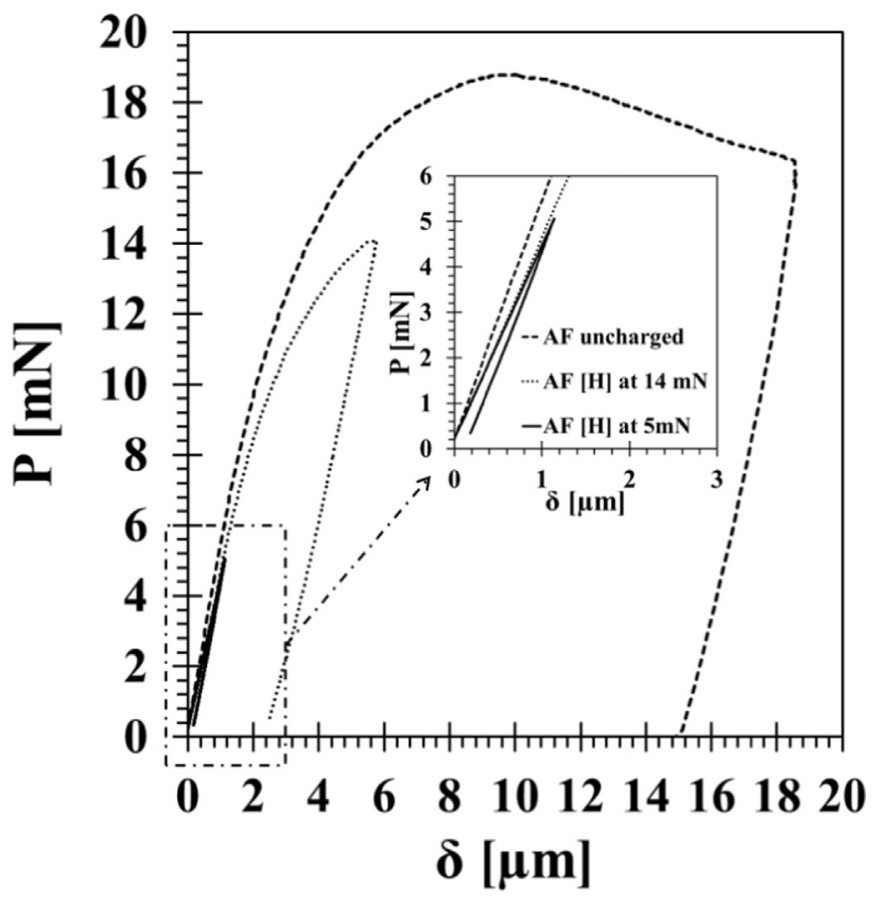

Fig. 7. Load-deflection curves for un-charged and pre-charged $[\mathrm{H}]$ acicular ferrite (AF) micro-cantilevers.

pre-charged sharply notched specimens. The uncharged specimen was loaded until failure. It was used to identify the critical failure load and identify the range of loading conditions for the hydrogen charged specimen. The hydrogen charged specimen was tested at constant loads of $5 \mathrm{mN}$ and $14 \mathrm{mN}$, which correspond to approximately $25 \%$ and $75 \%$ of the critical failure load for the uncharged specimen, respectively. These loads, in accordance with Eqs. (3)-(7), generated stress intensity factors values of respec- tively 1.56 and $4.36 \mathrm{MPa} \mathrm{m}^{1 / 2}$. Each of these loads was applied approximately within five minutes after completion of the hydrogen charging procedure and held constant for $12 \mathrm{~h}$.

The traditional crack growth monitoring method based on the measurement of specimen compliance [50] was not possible as Young's modulus changed during the prolonged tests. In the charged specimens Young's modulus was notably lower as indicated by lower values of the slope of the linear part of the loaddeflection diagram (Fig. 7). During unloading after $12 \mathrm{~h}$ of holding time, Young's modulus of pre-charged specimen has fully recovered to the corresponding value of the uncharged specimen. This indicates that hydrogen largely diffused out of the sample during the 12-h tests. Therefore, the crack growth (or absence of the crack propagation) was carefully evaluated from fractographic observations after the testing as presented below.

\subsection{Fractographic observations}

The fracture mode of the uncharged micro-cantilever was ductile and resulted in severe blunting of the notch tip (Fig. 8a), while an apparently brittle crack initiated from the notch tip of the hydrogen pre-charged micro-cantilever tested at the constant load of $14 \mathrm{mN}$ (Fig. 8b and c). The crack length of $1.55 \mu \mathrm{m}$ seemed thereby to be insufficient to cause cross-sectional failure. The fracture morphology of the crack was defined by tear ridges that followed the direction of the crack propagation (Fig. 8d-f). The opposing fracture surfaces matched thereby ridge to ridge. In addition, the high resolution secondary electron images in Fig. 8d-f also reveal that the hydrogen charging introduced some minor surface damage as evident in the regions adjacent to the crack path. No cracks, plastic deformations, deflection or changes to the original shape (Fig. 2) were observed for the pre-charged cantilever loaded at the constant load of $5 \mathrm{mN}$.
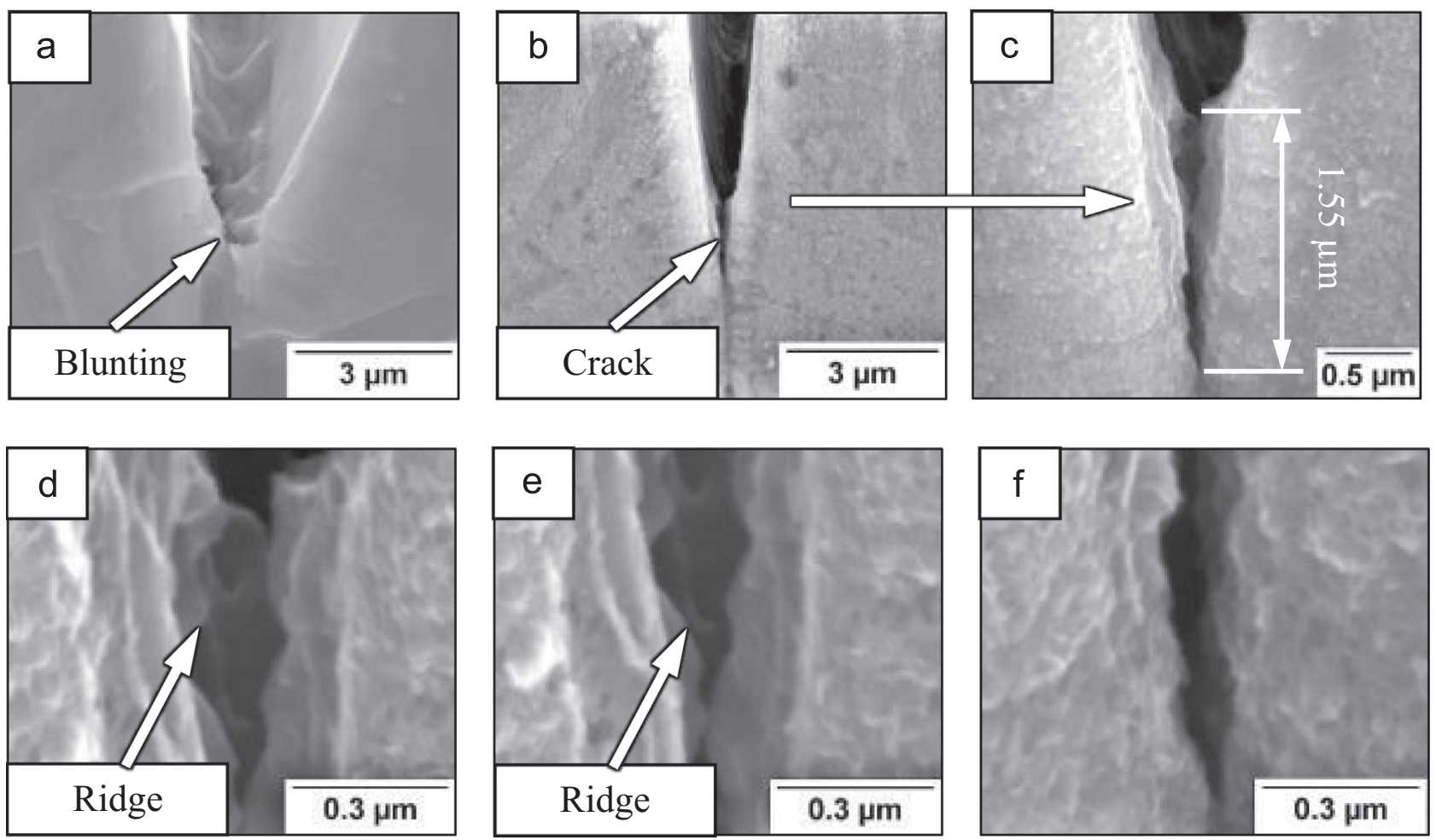

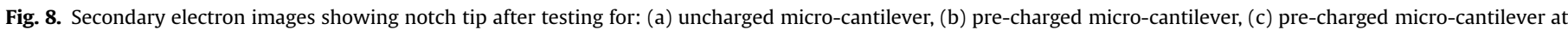
higher magnification. Secondary electron images showing the fracture surface morphologies at: (d) crack initiation, (e) crack propagation, (f) crack arrest. 


\section{Discussion}

The outcomes of testing the HACC susceptibility of the acicular ferrite are summarised in Table 3. This table also provides the corresponding values of stress intensity factors as calculated using the analytical approach presenter earlier (Section 2.5), as well as the averaged crack growth rate as evaluated from fractographic examinations.

From the conducted experiments it was not possible to identify precisely the value of $K_{\mathrm{th}}$. However, it can be stated that the threshold value ranges between 1.56 and $4.36 \mathrm{MPa} \mathrm{m}^{1 / 2}$. This identified range is significantly below the typical values of $K_{\text {th }}$ for low and medium carbon steels. Indeed, the threshold below which crack does not grow in X70 weld metal charged with a similar concentration of hydrogen has been reported to be around $147 \mathrm{MPa} \mathrm{m}^{1 / 2}$ [22]. In medium carbon steels having the values of yield strength close to those of the weld metal and acicular ferrite (i.e. between 580 and $830 \mathrm{MPa}$ ) the $K_{\mathrm{th}}$ was measured under various testing conditions between 42 and $88 \mathrm{MPa} \mathrm{m}^{1 / 2}[18,19]$. Similarly, for low carbon steels with yield strength values between 310 and $760 \mathrm{MPa}$ the $K_{\text {th }}$ laid typically between 37 and $78 \mathrm{MPa} \mathrm{m}^{1 / 2}[20,21]$. Appears a $K_{\mathrm{th}}$ nevertheless exists at the microstructural level, as no cracking was observed at the constant applied load of $5 \mathrm{mN}$ and the hydrogen was largely diffused out of the sample at the end of the test restricting further crack growth assisted by hydrogen.

At applied loading above $10 \mathrm{mN}$ the load deflection curves, for both charged and uncharged specimens, demonstrate a non-linear behaviour, which indicates that the near notch (crack) tip plastic zone becomes significant with respect to the sizes of the microcantilever. In this case non-linear fracture mechanics parameters, such as J-integral or crack opening displacement could be more appropriate for the characterisation of stress state near the crack tip. Based on the ASTM E1820 standard [51] a procedure for the evaluation of J-integral in micro-tests was provided in [50]. However, the stress intensity factor was used in our study as a measure of the intensity of strain-stress field at the notch tip to allow comparison with the corresponding values obtained from standard (macroscopic) tests.

Since dissolved monoatomic hydrogen occupies a specific volume within interstitial lattice sites, it tends to migrate from compressed to expanded regions within the crystal lattice until an equilibrium concentration profile is established [52]. Hydrostatic tensile stresses are hence a driving force for interstitial lattice diffusion of hydrogen towards the dilatation zone, which is located at the notch (crack) tip, where hydrogen may accumulate and thereby incrementally degrade the localised fracture resistance of the microstructure with time [53]. A sufficient level of hydrogen concentration necessary for failure formation may thus only occur periodically, in highly localised regions, explaining the slow crack growth rate. In these microscopic regions, failure may then occur either due to the formation of microvoids [2,14,54], or due to the formation of miniscule cracks $[11,12]$. In both cases the crack would propagate gradually due to ductile tearing (formation of tear ridges, as observed in Fig. 8d-f) if the remaining ligaments are too weak to accommodate the stresses. The crack growth rate was

Table 3

Summary of the micromechanical test parameters and results for acicular ferrite charged with $0.132 \mathrm{ppm}$ of hydrogen.

\begin{tabular}{rllll}
\hline $\begin{array}{l}\text { Load } \\
(\mathrm{mN})\end{array}$ & $\sigma(\mathrm{MPa})$ & $K_{I}\left(\mathrm{MPa} \mathrm{m}^{1 / 2}\right)$ & $\begin{array}{l}\text { Crack } \\
\text { growth }\end{array}$ & $\begin{array}{l}\text { Averaged crack growth rate } \\
\left(\mathrm{m} \mathrm{s}^{-1}\right)\end{array}$ \\
\hline 5 & 198.1 & 1.56 & no & - \\
14 & 550.8 & 4.36 & yes & $3.59 \times 10^{-11}$ \\
\hline
\end{tabular}

measured to be several orders of magnitudes lower than it is typically reported at the macroscopic level. Indeed, the lower bound values of subcritical crack growth near the threshold level were reported at around $10^{-9} \mathrm{~m} \mathrm{~s}^{-1}[18,21]$, and in our tests the crack growth rate averaged over $12 \mathrm{~h}$ was as low as $3.59 \times 10^{-11} \mathrm{~m} \mathrm{~s}^{-1}$.

A qualitative analysis of the load-deflection curves (Fig. 7) indicates that the yield strength and Young's modulus of hydrogen pre-charged specimen are lower. This implicates that hydrogen had caused a notable decrease of the both properties of the acicular ferrite microstructure since for charged specimens the slope of the linear part of load deflection diagrams is notably smaller and deviation from linear behaviour occurs much earlier. This behaviour can be explained within the microscopic theories developed in the past. The HELP (Hydrogen Enhanced Localized Plasticity) model (theory) $[2,14]$ provides a rational explanation for a decrease of the yield strength. This model postulates a hydrogen enhanced dislocation mobility which in turn may promote microscopic plastic deformation at lower stress levels. Also, the AIDE (Adsorption Induced Dislocation Emission) model [54] suggests that the weakening of the inter-atomic bonds at the crack tip facilitates the injection of dislocations which results in an extensive dislocation activity at the vicinity of the crack tip and may therefore also lead to a reduction of the localised yield strength. The observed decrease of the Young's modulus is also consistent with most of the previous results reported in the literature $[21,55,56]$, and it was attributed to the reduction of the cohesive energy of the iron lattice [55].

\section{Conclusion}

This work for the first time has demonstrated that microfracture tests can be successfully accomplished for an individual microstructural constituent within a very small material volume, pre-charged with hydrogen and under controlled loading conditions. For acicular ferrite, the selected constituent in this study, under pre-charged conditions with $0.132 \mathrm{ppm}$ of hydrogen, it was found that:

- The threshold stress intensity factor, $K_{\mathrm{th}}$, of acicular ferrite sourced from weld metal is well below the corresponding threshold for weld metal, low and medium carbon steels having similar yield strength levels. The $K_{\text {th }}$ values to initiate fracture propagation in acicular ferrite is measured between 1.56 $\mathrm{MPa} \mathrm{m}^{1 / 2}$ and $4.36 \mathrm{MPa} \mathrm{m}^{1 / 2}$, which is almost one and two order of magnitude lower than for carbon steels and weld metal, respectively. This finding is very intriguing as acicular ferrite is normally considered to be particularly beneficial for the strength and fracture toughness as well as for the WMHACC resistance of welded joints. However, the latter consideration was based on outcomes of testing macro-samples incorporating acicular ferrite together with other constituents rather than on a microsamples fully consisting of this microstructural constituent [34].

- The crack growth rates in the vicinity of the threshold, appear to be significantly lower than those reported from the previous macroscopic tests.

- The yield strength and the elastic modulus decreased with the presence of hydrogen, which is consistent with the most of previous macro- and micro-results reported in the literature.

In summary, the main outcome of the conducted tests is the demonstration that subcritical hydrogen cracks can grow at the micro-scale at stress intensity factors well below the stress intensity factor threshold measured with conventional tests at the macro-scale. It seems that all fracture toughening mechanisms may not be fully activated at the micro-scale. These mechanisms 
may include roughness or plasticity induced closure, which cannot be developed in micro-samples due to the limited crack growth increments [57].

This study was only limited to acicular ferrite as the main purpose was to demonstrate the possible miniaturisation of IHAC fracture testing at the scale of individual microstructural constituents. The comparison of HACC resistance of diverse microstructural constituents was beyond the scope of the current paper. However, the presented method can be applied to different types of materials and microstructures to study the susceptibility of individual constituents to hydrogen cracking as well as to probe the change of their intrinsic mechanical properties. These studies will contribute to the understanding of the fundamental microstructural factors that control the IHAC susceptibility of many metals and alloys and thus enable the design of more IHAC resistant materials through microstructural engineering by avoiding IHAC susceptible microstructural constituents and promoting IHAC resistant ones.

\section{Acknowledgements}

This work was funded by the Energy Pipelines CRC, supported through the Australian Government Cooperative Research Centres Program (RP1-02B). The funding and in-kind support from the APGA-RSC (81107701) is gratefully acknowledged. The authors would like to thank Rahim Kurji (Ph.D. Candidate) for the fabrication of the weld samples. The authors acknowledge the facilities, and the scientific and technical assistance of the Australian Microscopy \& Microanalysis Research Facility at the University of Adelaide, in particular its former director Mr. John Terlet, its current director Dr. Angus Netting, Mr. Leonard Green and Dr. Animesh Basak. Without their dedication and wealth of knowledge this work would not have been possible.

\section{References}

[1] W.H. Johnson, On some remarkable changes produced in iron and steel by the action of hydrogen and acids, Nature 11 (1875) 393.

[2] C.D. Beachem, A new model for hydrogen-assisted cracking (hydrogen "embrittlement"), Metall. Trans. 3 (1972) 441-455.

[3] R.P. Gangloff, Hydrogen assisted cracking of high strenght alloys, in: I. Milne, R. O. Richie, B. Karihaloo (Eds.), Comprehensive Structural Integrity, Elsevier Science, New York, 2003, pp. 31-101.

[4] S. Chu, A. Majumdar, Opportunities and challenges for a sustainable energy future, Nature 488 (2012) 294-303.

[5] A. Barnoush, H. Vehoff, Recent developments in the study of hydrogen embrittlement: Hydrogen effect on dislocation nucleation, Acta Mater. 58 (2010) 5274-5285.

[6] P.J. Ferreira, I.M. Robertson, H.K. Birnbaum, Hydrogen effects on the interaction between dislocations, Acta Mater. 46 (1998) 1749-1757.

[7] S.P. Lynch, Metallographic contributions to understanding mechanisms of environmentally assisted cracking, Metallography 23 (1989) 147-171.

[8] H. Vehoff, W. Rothe, Gaseous hydrogen embrittlement in FeSi- and Ni-single crystals, Acta Metall. 31 (1983) 1781-1793.

[9] M.L. Martin, I.M. Robertson, P. Sofronis, Interpreting hydrogen-induced fracture surfaces in terms of deformation processes: a new approach, Acta Mater. 59 (2011) 3680-3687.

[10] H.H. Johnson, A.R. Troiano, Crack initiation in hydrogenated steel, Nature 179 (1957) 777.

[11] A.R. Troiano, The role of hydrogen and other interstitials in the mechanical behaviour of metals, Trans. ASM 52 (1960) 54-80.

[12] R.A. Oriani, Testing of the decohesion theory of hydrogen induced crack propagation, Scr. Metall. 6 (1972) 681-688.

[13] R.A. Oriani, J.P. Hirth, M. Smialowski, Hydrogen Degradation of Ferrous Alloys, Noyes, Park Ridge, NJ, USA, 1985.

[14] H.K. Birnbaum, P. Sofronis, Hydrogen-enhanced localized plasticity-a mechanism for hydrogen-related fracture, Mat. Sci. Eng. A 176 (1994) 191-202.

[15] S.P. Lynch, Hydrogen embrittlement (HE) phenomena and mechanisms, in: V S. Raja, T. Shoji (Eds.), Stress Corrosion Cracking: Theory and Practice, Woodhead Publishing Ltd., Cambridge, 2011, pp. 90-126.

[16] J.M. Barsom, S.T. Rolfe, Fracture and Fatigue Control in Structures, 2nd Ed., Prentice-Hall, Englewood Cliffs, NJ, 1987.
[17] B.F. Brown, C.D. Beachem, A study of the stress factor in corrosion cracking by use of the precracked cantilever-beam specimen, Corros. Sci. 5 (1965) 745-750.

[18] A.W. Loginow, E.H. Phelps, Steels for seamless hydrogen pressure vessels, Corrosion 31 (1975) 404-412.

[19] W.W. Gerberich, Y.T. Chen, A threshold stress intensity concept for environmental cracking, Int. J. Fract. 9 (1973) 369-371.

[20] G.-H. Yu, B.-L. Jiang, L.-J. Qiao, Y.-B. Wang, W.-Y. Chu, Threshold stress intensity for hydrogen-induced cracking of tubular steel, Scr. Mater. 12 (1997) 1467-1470.

[21] S. Homrossukon, S. Mostovoy, J.A. Todd, Investigation of hydrogen assisted cracking in high and low strength steels, J. Press. Vessel Technol.: Trans. ASME 131 (2009) 1-11.

[22] V. Olden, A. Alvaro, O.M. Akselsen, Hydrogen diffusion and hydrogen influenced critical stress intensity in an API X70 pipeline steel welded joint - experiments and FE simulations, Int. J. Hydrog. Energy 37 (2012) 11474-11486.

[23] ASTM, Standard Test Method for Determining a Threshold Stress Intensity Factor for Environment-Assisted Cracking of Metallic Materials, Designation E1681-99, vol. 03.01, ASTM International, West Conshohocken, PA, 2000.

[24] Y. Katz, N. Tymiak, W.W. Gerberich, Nanomechanical probes as new approaches to hydrogen/deformation interaction studies, Eng. Fract. Mech. 68 (2001) 619-646.

[25] D. Di Maio, S.G. Roberts, Measuring fracture toughness of coatings using focused-ion-beam-machined microbeams, J. Mater. Res. 20 (2005) 299-302.

[26] M. Deutges, I. Knorr, C. Borchers, C.A. Volkert, R. Kirchheim, Influence of hydrogen on the deformation morphology of vanadium (100) micropillars in the $\alpha$-phase of the vanadium-hydrogen system, Scr. Mater. 68 (2013) 71-74.

[27] N. Kheradmand, J. Dake, A. Barnoush, H. Vehoff, Novel methods for micromechanical examination of hydrogen and grain boundary effects on dislocations, Philos. Mag. 92 (2012) 3216-3230.

[28] S. Wurster, C. Motz, M. Jenko, R. Pippan, Micrometer-sized specimen preparation based on ion slicing technique, Adv. Eng. Mater. 12 (2010) 61-64.

[29] B.N. Jaya, V. Jayaram, Fracture testing at small-length scales: from plasticity in Si to brittleness in Pt, JOM: J. Miner. Met. Mater. Soc. (2015), http://dx.doi.org/ 10.1007/s11837-015-1489-2.

[30] J.L. Davidson, S.P. Lynch, A. Majumdar, in: J.L. Davidson, D.L. Olson (Eds.), Hydrogen Managament in Steel Weldments, The Organising Committee of the Joint Seminar on behalf of Defence Science and Technology Association and Welding Technology Institute of Australia Melbourne, Australia, 1997.

[31] N. Yurioka, H. Suzuki, Hydrogen assisted cracking in C-Mn and low alloy steel weldments, Int. Mater. Rev. 35 (1990) 217-249.

[32] R. Ghomashchi, W. Costin, R. Kurji, Evolution of weld metal microstructure in shielded metal arc welding of X70 HSLA steel with cellulosic electrodes: a case study, Mater. Charact. 107 (2015) 317-326.

[33] N. Alam, H. Li, L. Chen, D. Dunne, B. Feng, I. Squires, F.J. Barbaro, Fracturemicrostructure relationships of hydrogen assisted cracking in steel weldments, Mater. Res. 3 (1996) 74-78.

[34] E. Mazancová, Z. Rucká, K. Mazanec, Comparison of microfractographic behaviour of acicular ferrite and bainite and hydrogen cracking resistance, Arch. Mater. Sci. 28 (2007) 95-99.

[35] W.L. Costin, O. Lavigne, V. Linton, I.H. Brown, A.G. Kotousov, F.J. Barbaro, R. Ghomashchi, Micromechanical examination of the relationship between weld metal microstructure and hydrogen assisted cold cracking (Paper no.: S10-02), in: Proceedings of the 6th International Pipeline Technology Conference, Ostend, Belgium, October 2013.

[36] J.F. Ziegler, J.P. Biersack, U. Littmark, The Stopping Power and Range of Ions in Solids, Pergamon Press, New York, 1985.

[37] D. Kiener, C. Motz, M. Rester, M. Jenko, G. Dehm, FIB damage of Cu and possible consequences for miniaturized mechanical tests, Mater. Sci. Eng. 459 (2007) 262-272.

[38] J. Ast, T. Przybilla, V. Maier, K. Durst, M. Göken, Microcantilever bending experiments in NiAl - evaluation, size effects, and crack tip plasticity, J. Mater. Res. 29 (2014) 2129-2140.

[39] M. Yan, Y. Weng, Study on hydrogen absorption of pipeline steel under cathodic charging, Corros. Sci. 48 (2006) 432-444.

[40] J. Capelle, I. Dmytrakh, Z. Azari, G. Pluvinage, Evaluation of electrochemical hydrogen absorption in welded pipe with steel API X52, Int. J. Hydrog. Energy 38 (2013) 14356-14363.

[41] T.H. Nam, J.G. Kim, Y.S. Choi, Electrochemical hydrogen discharge of highstrength low alloy steel for high-pressure gaseous hydrogen storage tank: effect of discharging temperature, Int. J. Hydrog. Energy 38 (2013) 999-1003.

[42] G. Thewlis, Classification and quantification of microstructures in steels, Mater. Sci. Technol. 20 (2004) 143-160.

[43] Z. Nishiyama, X-ray Investigation on the Mechanism of the Transformation From Face-centered Cubic Lattice to Body-centered Cubic Lattice, Science Report of the Tohoku Imperial University, no. 23, 1934, pp. 637-664.

[44] G. Wassermann, Über den Mechanismus der $\alpha-\gamma$ Umwandlung des Eisens', Mitteilungen aus dem Kaiser-Wilhelm-Institut für Eisenforschung, no. 17, 1935, pp. 149-155

[45] S.H. Hashemi, Strength-hardness statistical correlation in API X65 steel, Mater. Sci. Eng. A 528 (2011) 1648-1655.

[46] M.-C. Zhao, K. Yang, Y.-Y. Shan, Comparison on strength and toughness behaviors of microalloyed pipeline steels with acicular ferrite and ultrafine ferrite, Mater. Lett. 57 (2003) 1496-1500.

[47] Y. Weng, Ultra-Fine Grained Steels, Co-published by Mettalurgical Industry Press, Beijing and Springer-Verlag GmbH Berlin Heidelberg, Beijing, New York, 
2009, p. 26.

[48] M. Diaz-Fuentes, A. Iza-Mendia, I. Guttierez, Analysis of different acicular ferrite microstructures in low-carbon steels by electron backscattered diffraction. Study of their toughness behavior, Metall. Mater. Trans. A 34A (2003) 2505-2516.

[49] L. Shi, Z. Yan, Y. Liu, C. Zhang, Z. Qiao, B. Ning, H. Li, Improved toughness and ductility in ferrite/acicular ferrite dual-phase steel through intercritical heat treatment, Mater. Sci. Eng. A 590 (2014) 7-15.

[50] S. Wurster, C. Motz, R. Pippan, Characterization of the fracture toughness of micro-sized tungsten single crystal notched specimens, Philos. Mag. 92 (2012) 1803-1825.

[51] ASTM, Standard Test Method for Measurement of Fracture Toughness, Designation E1820-13E01, ASTM International, West Conshohocken, PA, 2013.
[52] R. Kirchheim, Solid State Physics, Academic Press, Cambridge, MA, USA, 2004.

53] I.M. Bernstein, The role of hydrogen in the embrittlement of iron and steel, Mater. Sci. Eng. 6 (1970) 1-19.

[54] S.P. Lynch, Environmentally assisted cracking: overview of evidence for an adsorption-induced localised-slip process, Acta Met. 36 (1988) 2639-2661.

[55] M. Ortiz, J. Ovejero-Garcia, Effect of hydrogen on Young's modulus of AISI 1005 and 1070 steels, J. Mater. Sci. 27 (1992) 6777-6781.

[56] D. Psiachos, T. Hammerschmidt, R. Drautz, Ab initio study of the modification of elastic properties of $\alpha$-iron by hydrostatic strain and by hydrogen interstitials, Acta Mater. 59 (2011) 4255-4263.

[57] J. Codrington, A. Kotousov, A crack closure model of fatigue crack growth in plates of finite thickness under small-scale yielding conditions, Mech. Mater 41 (2) (2009) 165-173. 